\title{
Linking supply chain quality integration with mass customization and product modularity
}

\begin{abstract}
Supply chain quality management has received increasing attention from researchers and practitioners in recent years. However, the knowledge about the effects of a manufacturer's design and production capabilities on supply chain quality management is limited. In this study, we propose a model to investigate the effects of mass customization and product modularity on supply chain quality integration (i.e. internal, supplier, and customer quality integration) and the impact of supply chain quality integration on competitive performance. We use data collected from 317 manufacturers to empirically test the research model. The results show that mass customization and product modularity directly improve internal quality integration, and product modularity also improves internal quality integration indirectly through mass customization. Product modularity improves supplier quality integration directly, and both mass customization and product modularity improve supplier quality integration indirectly through internal quality integration. Mass customization improves customer quality integration both directly and indirectly through internal quality integration, and product modularity improves customer quality integration indirectly through mass customization and internal quality integration. We also find that supplier quality integration directly enhances competitive performance, and internal quality integration enhances competitive performance both directly and indirectly through supplier quality integration.
\end{abstract}

Keywords: Supply chain quality integration; Mass customization; Product modularity; Competitive performance 


\section{Introduction}

Along with the globalization of production, supply chains have become crucial sources of quality issues (Flynn and Zhao, 2015; Foster, 2008; Robinson and Malhotra, 2005). As a quality problem can be caused by any link in a manufacturer's supply chain, many traditional quality management practices, such as monetary incentives, training, and sharing of best practices, may have limited effects on reducing quality risks (Srinivasan and Kurey, 2014). Researchers argue that quality management must take a supply chain perspective (Flynn and Flynn, 2005; Yeung, 2008; Robinson and Malhotra, 2005). Supply chain quality management extends the company-centric and product-based practices to emphasize formal coordination and integration of business processes, in order to continually improve the quality of products, services, and processes (Huo et al., 2014). To deliver value to customers in a globally dispersed supply chain, manufacturers must develop an integrated quality system to synchronize decisions and activities of supply chain partners and leverage opportunities created by linkages with suppliers and customers (Foster, 2008; Huo, 2012; Srinivasan and Kurey, 2014).

By linking quality management with supply chain integration, supply chain quality integration can be defined as "the degree to which an organization's internal functions and external supply chain partners strategically and operationally collaborate with each other to jointly manage intra- and inter-organizational quality-related relationships, communications, processes, etc., with the objective to achieve high levels of quality-related performance at low costs" (Huo et al., 2014:39). Supply chain quality integration includes internal, supplier, and customer quality integration, capturing both internal and external supply chain contexts (Sila et al., 2006). Researchers argue that collaborating with supply chain partners on quality management improves performance outcomes (Huo et al., 2014; Lin et al., 2005; Romano and Vinelli, 2001; Sila et al., 2006; Yeung, 2008). Supply chain integration literature further reveals 
that integration with customers and suppliers may influence performance outcomes in different ways (Flynn et al., 2010; Zhao et al., 2013). However, the majority of empirical quality management studies fail to identify the distinctive effects of internal, supplier, and customer quality integration on competitive performance (Flynn and Zhao, 2015; Huo et al., 2014). In addition, there is limited empirical evidence on how to establish an integrated system to improve quality in a supply chain.

Mass customization refers to the capability to reliably offer a high volume of different product options in a relatively large market that demands customization, without substantial trade-offs in cost, delivery, and quality (Liu et al., 2006; Tu et al., 2001). It has four components: high volume customization, customization cost efficiency, customization responsiveness, and customization quality (Kristal et al., 2010; Lai et al., 2012; Liu et al., 2012a). Mass customization capability enables manufacturers to achieve multiple competitive priorities simultaneously (Da Silveira et al., 2001; Huang et al., 2008; Liu et al., 2006) and to resolve trade-offs between customization and costs (Kortmann et al., 2014; Zhang et al., 2015b). Indeed, researchers report that the implementation of mass customization improves various performance outcomes, such as value to customers (Tu et al., 2001), customer satisfaction (Liu et al., 2012a), operational performance in terms of cost, quality, delivery, and flexibility (Kortmann et al., 2014; Liu et al., 2012b), product innovation (Zhang et al., 2015a), and firm performance (Jitpaiboon et al., 2013; Zhang et al., 2015b).

Product modularity is "the practice of using standardized modules so they can be easily reassembled/rearranged into different functional forms, or shared across different product lines" (Tu et al., 2004:151). A module product design is characterized by component commonality, component combinability, function binding, interface standardization, and loose coupling (Salvador, 2007). The capability of modularizing products enables manufacturers to develop products from subsystems that can be designed independently and then be reconfigured into 
new products and associated processes, allowing economies of scale and scope across product lines (Baldwin and Clark, 1997; Duray et al., 2000). Product modularity allows manufacturers to cope with rapidly changing customer requirements and increasing technical complexity in production processes and supply chains which allow the manufacturers to achieve quick response and high flexibility (Peng et al., 2011; Salvador, 2007). Researchers argue that the implementation of mass customization and product modularity drives manufacturers to rethink and redesign their supply chains as integrated systems (Da Silveira et al., 2001; Fogliatto et al., 2010; Zhang et al., 2015b). However, current studies mainly focus on how to develop mass customization capability and the effect of product modularity on manufacturing processes (e.g. Tu et al., 2004; Liu et al., 2006; Huang et al., 2008; Peng et al., 2011; Zhang et al., 2015a; Zhang et al., 2014). Empirical studies that link mass customization and product modularity with quality management are scant and few have investigated their effects on supply chain quality integration (Kristal et al., 2010).

The objective of this study is to empirically investigate the enabling roles of mass customization and product modularity in supply chain quality integration. This study addresses three research questions. First, how does mass customization influence supplier, internal, and customer quality integration? Second, how does product modularity influence supplier, internal, and customer quality integration? Third, how do supplier, internal, and customer quality integration affect competitive performance?

The remainder of this paper is organized as follows. In Section 2, we develop the research hypotheses and conceptual model. The research methodology is described in Section 3 and the empirical analyses and results are presented in Section 4. In Section 5, we discuss the key findings of the study and their theoretical contributions and managerial implications, and outline the limitations and future research directions. 


\section{Research hypotheses}

\subsection{The effects of mass customization on supply chain quality integration}

Mass customizers can respond to an increasingly uncertain, competitive, and complex environment and align their businesses with customer requirements (Fogliatto et al., 2010; Salvador et al., 2009; Zhang et al., 2015c). They usually implement advanced channel management, inventory management, and production planning techniques, build lateral relations for internal interactions, and actively manage environments by cooperating with supply chain partners (Trentin et al., 2012; Jitpaiboon et al., 2013). They also develop a system to elicit information from environments and identify the attributes of solution spaces, apply flexible process technologies to reuse and recombine existing resources, and build an integrated logistics system (Fogliatto et al., 2010; Salvador et al., 2009; Zhang et al., 2015b). Hence, mass customization can improve a manufacturer's operational capabilities (Kortmann et al., 2014; Zhang et al., 2015a). Indeed, researchers argue that mass customization can provide sustainable competitive advantages to a manufacturer (Kortmann et al., 2014; Liu et al., 2012b). Therefore, mass customizers have abilities, resources, and power to exert influence over partners and can become leaders in supply chains (Da Silveira et al., 2001; Fogliatto et al., 2010; Zhang et al., 2015b).

Supply chain leadership increases supply chain partners' compliance with and commitment to the leader's vision for the entire supply chain (Flynn and Zhao, 2015). Hence, mass customizers can create leadership that emphasizes quality (Srinivasan and Kurey, 2014) and develop quality management strategies that encompass upstream and downstream supply chains as well as internal operations (Foster, 2008; Kaynak and Hartley, 2008). Supplier/customer quality integration can be defined as the degree to which an organization integrates with its suppliers/customers to structure inter-organizational strategies, practices, and procedures into collaborative and synchronized quality-related processes to fulfil its 
customers' quality requirements (Flynn et al., 2010; Huo et al., 2014). As supply chain leaders, mass customizers can attach high importance to quality, which leads to a common understanding on quality issues among partners, improving supplier/customer quality integration (Foster, 2008). In particular, customization responsiveness drives a manufacturer to keep close communications with suppliers on quality considerations and design changes (Kortmann et al., 2014). Customization quality motivates a manufacturer to select suppliers with quality certifications and collaborate with suppliers to improve quality (Flynn and Flynn, 2005). High volume customization and customization cost efficiency prompt a manufacturer to integrate with suppliers to develop new products and processes (Trentin et al., 2012). In addition, mass customizers tend to keep close contact with customers to elicit customer requirements and feedback on product quality (Fogliatto et al., 2010; Zhang et al., 2015b). Customization also drives a manufacturer to work together with customers on new product development and quality improvement (Zhang et al., 2015a). Hence, mass customization lays the foundation for learning from customers (Salvador et al., 2009). Internal quality integration refers to the "degree to which an organization structures its own strategies, practices and procedures into collaborative, synchronized processes to fulfil its customers' quality requirements" (Huo et al., 2014:39). Mass customization is closely related to organizational designs encouraging communication, cooperation, and peer involvement (Da Silveira et al., 2001; Trentin et al., 2012). Hence, employees in different functional departments are encouraged to coordinate their quality management decisions and activities (Yeung et al., 2009; Zhao et al., 2013). Cross-functional teams are more likely to be formed to solve quality problems (Sila et al., 2006; Flynn et al., 2010). Therefore, we propose the following hypotheses. H1a: Mass customization is positively related to supplier quality integration. H1b: Mass customization is positively related to internal quality integration. H1c: Mass customization is positively related to customer quality integration. 


\subsection{The effects of product modularity on supply chain quality integration}

Product modularity enables a manufacturer to improve supply chain transparency because modular product designs can reduce information asymmetries in a supply chain (Baldwin and Clark, 1997; Peng et al., 2011). The degree of product modularity also significantly influences a manufacturer's channel management and production planning techniques, and supply chain design decisions regarding the structures of production and logistics networks, processes along the supply chain, and relationships among supply chain members (Tu et al., 2004; Peng et al., 2011). When a product is composed of standard modules, an effective product architecture can be created and its supply chain becomes less complex, which reduces difficulties in assessing the quality of components (Flynn and Flynn, 2005; Sila et al., 2006). A manufacturer can also schedule and control production and supply chain processes efficiently (Salvador, 2007). Product modularity thus enables manufacturers to include quality considerations when making decisions concerning supply chain designs (Flynn and Zhao, 2015).

Product modularity enables a manufacturer to efficiently and effectively design supply chains to meet quality targets (Flynn and Zhao, 2015). Such supply chain designs facilitate manufacturers to incorporate quality considerations when selecting supply chain partners, developing inter-organizational processes, building supply chain relationships, and making long-term investment decisions on the locations and ownerships of supply chain operations (Flynn et al., 2010; Kaynak and Hartley, 2008). They also increase the visibility of supply chains and the testability of products and help a manufacturer to establish a tracking and tracing system throughout supply chains, improving supply chain quality integration. In particular, a manufacturer must maintain close interactions with suppliers to decide interface specifications to ensure the combinability of modules (Peng et al., 2011). Product modularity also prompts a manufacturer to collaborate with suppliers on new product development because modules must have compatible specifications and standards (Lai et al., 2012; Zhang et al., 2014). Combining 
or configuring standard modules into customized products requires the coordination and cooperation of employees from various departments, such as marketing, product development, and manufacturing (Duray et al., 2000; Peng et al., 2011). When making decisions on the specifications of modules, cross-functional teams play important roles because functional departments may have different interests and priorities (Lai et al., 2012). Moreover, product modularity drives a manufacturer to learn from customers because the feedback and suggestions acquired from customers help a manufacturer to improve the designs of modules as well as recombine modules in innovative ways (Zhang et al., 2015c). Product modularity also decomposes complex products into simple modules and divides product designs into selfcontained tasks, facilitating customer involvement in product development and quality improvement (Duray et al., 2000). Therefore, we propose the following hypotheses.

H2a: Product modularity is positively related to supplier quality integration.

H2b: Product modularity is positively related to internal quality integration.

H2c: Product modularity is positively related to customer quality integration.

\subsection{The effects of supply chain quality integration on competitive performance}

Competitive performance reflects a manufacturer's overall capabilities to gain competitive advantages (Zhao et al., 2013). Following Miller and Roth (1994), competitive performance is conceptualized as a manufacturer's performance on a mix of objectives including cost, quality, flexibility, delivery, and innovation (Zhao et al., 2013). Researchers find that upstream quality management significantly improves firm performance (Huo et al., 2014; Kaynak and Hartley, 2008; Lin et al., 2005). Supplier quality integration not only improves supply chain transparency and suppliers' quality management capabilities, but also aligns objectives and goals between a manufacturer and suppliers, enhancing competitive performance (Flynn and Zhao, 2015). In particular, cooperative relationships and close communications with suppliers ensure that suppliers fully understand the importance of quality (Srinivasan and Kurey, 2014). 
Supplier certification and development can further improve the quality of materials and components sourced from suppliers. High quality components can prevent errors that slow down throughput speed and that cause internal unreliability, low dependability, and wasted times and efforts, thus saving costs and improving delivery (Yeung, 2008; Robinson and Malhotra, 2005). Involving suppliers in quality improvement and new product development enables a manufacturer to use suppliers' resources and capabilities, which can not only avoid mismatches among different components but also reduce costs and lead times for new product development (Romano and Vinelli, 2001; Yeung et al., 2009).

Internal quality integration facilitates lateral communications on quality issues and enables different functional departments to coordinate quality decisions (Srinivasan and Kurey, 2014; Zhang et al., 2014). Hence, a manufacturer can make fewer mistakes and less confusion and irritation will be spread, leading to stable and efficient processes and improved internal visibility (Yeung, 2008). In addition, cross-functional interactions and cooperation push everyone in a manufacturer to take responsibility for quality which reduces variation in production and smoothens processes, reducing manufacturing costs and inventory levels (Flynn and Zhao, 2015; Lai et al., 2012). Functional departments can thus work cooperatively under the same quality criteria, speeding up new product development and delivery (Huo et al., 2014). Problem solving teams can break down functional barriers and employees from different departments can work together to solve conflict related to manufacturing, innovation, and delivery processes, which decreases costs, increases flexibility, and improves quality (Flynn et al., 2010).

Customer quality integration enables a manufacturer to develop a good understanding of customer requirements, which reduces design errors (Kaynak and Hartley, 2008). A manufacturer can thus provide customers with reliable products (Flynn and Flynn, 2005; Huo et al., 2014). Frequent customer contact and qualification can lead to agreements on quality 
requirements and product specifications between a manufacturer and customers, which reduce market uncertainties and gaps between customers' perception and expectation on quality (Foster, 2008; Zhang et al., 2015c). Customer involvement enables a manufacturer to use customers' resources and skills in new product development and quality improvement, enhancing flexibility and innovativeness (Lai et al., 2012; Zhang et al., 2014). Feedback from customers on quality and delivery performance improves the visibility and traceability of products, reducing the negative impacts of quality problems (Flynn and Zhao, 2015). In addition, participating in customers' quality improvement projects ensures that products can be distributed, stored, and handled in appropriate conditions, preventing potential quality problems (Flynn and Flynn, 2005; Zhao et al., 2013). Therefore, we propose the following hypotheses.

H3a: Supplier quality integration is positively related to competitive performance.

H3b: Internal quality integration is positively related to competitive performance.

H3c: Customer quality integration is positively related to competitive performance.

\subsection{Conceptual model}

Product modularity is a design capability closely associated with the implementation of mass customization (Duray et al., 2000; Peng et al., 2011). Product modularity enables a manufacturer to fulfil customized demands by mixing-and-matching standard components, allowing the manufacturer to achieve high product and mix flexibility with low production costs and high speed to market (Baldwin and Clark, 1997; Salvador et al., 2009). In addition, empirical evidence exists that product modularity is positively associated with mass customization capability (Tu et al., 2004; Peng et al., 2011; Zhang et al., 2014). Therefore, we include the positive impact of product modularity on mass customization in the conceptual model.

Internal quality integration enables a manufacturer to integrate functional departments and 
internal processes to achieve quality improvement (Flynn et al., 2010; Flynn and Zhao, 2015). It can lead to common understandings on how to balance quality with cost reduction and quick delivery in operations and consensus on organizational priorities and objectives (Zhang et al., 2014), which can create a culture of quality (Kaynak and Hartley, 2008; Srinivasan and Kurey, 2014). Hence, internal quality integration enables a manufacturer to accommodate core quality competencies derived from cooperative relationships with suppliers and customers and to involve them in internal operations such as new product development and quality improvement projects (Foster, 2008; Lin et al., 2005; Sila et al., 2006). It can also facilitate information exchange with suppliers and customers (Flynn and Zhao, 2015; Sila et al., 2006). In addition, there is empirical evidence that internal quality integration improves supplier and customer quality integration (Huo et al., 2014). Therefore, we include the positive effects of internal quality integration on supplier and customer quality integration in the conceptual model. The conceptual model and proposed hypotheses are presented in Figure 1.

$=====$ Insert Figure 1 about Here $=====$

\section{Research methodology}

We adopted the philosophy of positivism in this study (Bryman and Bell, 2011; Saunders et al., 2012). This study considered the relationships among mass customization, product modularity, supply chain quality integration, and competitive performance as observable reality and tended to create law-like generalizations. We developed hypotheses using existing theories and maintained an objective stance during the study (Saunders et al., 2012). The survey method was used to collect a large amount of quantitative data from a sizeable population, allowing us to test and explain the relationships between the variables (Bryman and Bell, 2011). The data was obtained using a questionnaire administered to a sample and then analysed quantitatively using statistical methods (Saunders et al., 2012). Therefore, the positivist 
quantitative approach was used in this study (Bryman and Bell, 2011; Saunders et al., 2012).

\subsection{Data}

Data used in this study were taken from the third round high performance manufacturing (HPM) project, which was conducted by a team of researchers in America, Asia, and Europe (Zhao et al., 2013; Zhang et al., 2014). The HPM database used for this study included 317 manufacturing plants in ten countries (i.e. Austria, China, Finland, Germany, Italy, Japan, Spain, South Korea, Sweden, and U.S.A.). These countries were selected because they represent different national cultures, economic conditions, and competitive environments around the world. The sample included plants in electronics, machinery, and auto-supplier industries. The plants in the HPM database were randomly selected from a master list of manufacturing plants in each of the countries. The plants each had at least 250 employees, as small and mediumsized manufacturers seldom engage in sophisticated supply chain management. We only included one plant per business unit or corporation. Table 1 provides a breakdown of the sample by country and industry.

$======$ Insert Table 1 about Here $======$

The target plants were initially contacted by telephone and follow-ups were conducted through a series of visits to the plants. A plant research coordinator was then appointed to distribute and collect questionnaires. The response rate was approximately $65 \%$, which reduces the need to check for non-response bias (Huang et al., 2008). Multiple supervisors and managers in each plant who were responsible for quality issues, such as inventory manager, product development manager, process engineer, plant manager, quality manager, supervisor, and plant superintendent, completed questionnaires (Appendix A). Survey items were divided between questionnaires to obtain the most comprehensive information from informants based on their job titles. This multiple-informant approach prevents problems caused by singlerespondent bias (Liu et al., 2006). Since the unit of analysis is plant, only the average for each 
scale across a set of questionnaires was used in subsequent analyses (Lai et al., 2012; Peng et al., 2011).

\subsection{Measures}

The measures were prepared in English and then translated into the local language of each country by a member of the research team. They were then checked for accuracy following the conventional back-translation process. The measures were developed based on the literature and had underwent rigorous pilot tests and psychometric tests (e.g. Huo et al., 2014; Peng et al., 2011; Zhang et al., 2014; Zhao et al., 2013).

Five items were used to measure the four components of mass customization: high volume customization, customization cost efficiency, customization responsiveness, and customization quality (Peng et al., 2011; Zhang et al., 2014). Product modularity was measured using three items related to the application of product platforms and common modules in product design (Zhang et al., 2014). The measurement for supply chain quality integration was adopted from Huo et al. (2014). In particular, supplier quality integration was measured using seven items about cooperative supplier relationships, supplier communications, supplier involvement in product design and quality improvement, and supplier certification; internal quality integration was measured using eight items related to the degree to which functional departments work together and coordinate with each other, and the use of teamwork to solve quality problems; and customer quality integration was measured using five items about cooperative customer relationships, customer communications, customer involvement in product design and quality improvement, and customer certification. Seven-point Likert-type scales ( $1=$ "strongly disagree"; 7= "strongly agree") were used to measure these constructs. The measurement for competitive performance was adapted from Zhao et al. (2013). Ten items were used to capture a manufacturer's performance in terms of cost, quality, flexibility, delivery, and innovation in comparison with its competitors in the industry. A five-point Likert-type scale ( $1=$ being "poor, 
low end of the industry"; 5 = being "superior") was used to measure competitive performance. The scales, which consist of 38 measurement items, and informants for each scale, are listed in Appendix A.

\subsection{Reliability and validity}

Table 2 shows the correlations between constructs and the Cronbach's Alpha, composite reliability, and average variance explained (AVE) of each construct. The values of Cronbach's Alpha ranged from 0.74 to 0.88 and the composite reliabilities ranged from 0.84 to 0.90 , which were all above the recommended threshold value of 0.70 , suggesting adequate reliability (Fornell and Larcker, 1981).

Convergent and discriminant validity was assessed using AVE and confirmatory factor analysis (CFA) (O'Leary-Kelly and Vokurka, 1998). All of the AVE values were above the recommended value of 0.50 except for one construct which was slightly lower (Table 2), demonstrating adequate convergent validity (Fornell and Larcker, 1981; Huang et al., 2008). In the CFA model, each item was linked to its corresponding construct and covariances among the constructs were freely estimated. The model fit indices were $\chi^{2}(650)=1215.03$, Comparative Fit Index $(\mathrm{CFI})=0.94$, Non Normed Fit Index $(\mathrm{NNFI})=0.94$, and Root Mean Square Error of Approximation $(\mathrm{RMSEA})=0.058$, indicating that the model was acceptable (Hu and Bentler, 1999). All factor loadings were greater than 0.50 except for one item which was slightly lower (ranging from 0.481 to 0.851 ) and all t-values were greater than 2.0 (ranging from 7.571 to 48.677). Therefore, convergent validity is achieved (O'Leary-Kelly and Vokurka, 1998). To assess discriminant validity, we built a series of constrained CFA models in which covariances among each pair of constructs were fixed to 1.0. The models were compared with the original unconstrained model, in which the covariances were freely estimated. The results showed that $\chi^{2}$ differences were all significant at the 0.01 level, indicating discriminant validity (Fornell and Larcker, 1981). A comparison of all of the correlations and square roots 
of the AVEs also indicated adequate discriminant validity for all constructs (Table 2).

$=====$ Insert Table 2 about Here $======$

\section{Analyses and results}

Structural equation modelling (SEM) with maximum likelihood estimation method is used to test the research model (Huang et al., 2008). To control for industry and country effects, we standardize the data by industry and country (Liu et al., 2006; Zhao et al., 2013). The model fit indices are $\chi^{2}(3)=5.89, \mathrm{CFI}=0.94, \mathrm{NNFI}=0.92$, and $\mathrm{RMSEA}=0.059$, indicating that the model can be accepted (Hu and Bentler, 1999). The standardized coefficients are presented in Figure 2. The results reveal that mass customization significantly improves internal $(\beta=0.34, p<0.05)$ and customer $(\beta=0.12, \mathrm{p}<0.05)$ quality integration, which provide support for $\mathrm{H} 1 \mathrm{~b}$ and $\mathrm{H} 1 \mathrm{c}$. However, its impact on supplier quality integration is not significant. Hence, H1a is not supported. The findings indicate that product modularity significantly enhances supplier $(\beta=0.16, p<0.05)$ and internal $(\beta=0.22, \mathrm{p}<0.05)$ quality integration. However, its impact on customer quality integration is not significant. Hence, $\mathrm{H} 2 \mathrm{a}$ and $\mathrm{H} 2 \mathrm{~b}$ are supported, but $\mathrm{H} 2 \mathrm{c}$ is not. Supplier $(\beta=0.14, \mathrm{p}<0.05)$ and internal $(\beta=0.33, \mathrm{p}<0.05)$ quality integration significantly improve competitive performance, whereas the effect of customer quality integration is not significant. Therefore, $\mathrm{H} 3 \mathrm{a}$ and $\mathrm{H} 3 \mathrm{~b}$ are supported, but $\mathrm{H} 3 \mathrm{c}$ is not. In addition, the results show that product modularity significantly enhances mass customization $(\beta=0.27, p<0.05)$ and that internal quality integration significantly improves supplier $(\beta=0.48, \mathrm{p}<0.05)$ and customer $(\beta=0.47, \mathrm{p}<0.05)$ quality integration.

$=====$ Insert Figure 2 about Here $=====$

Based on the SEM estimates, we further investigate the relationships among mass customization, product modularity, supply chain quality integration, and competitive performance by examining the indirect effects, with their significance levels determined by the bias-corrected bootstrap method using a 95\% confidence level and employing 5000 samples 
(Preacher and Hayes, 2008). The results show that the bias-corrected 95\% confidence intervals of the indirect effects of mass customization on supplier and customer quality integration through internal quality integration are $(0.15,0.28)$ and $(0.12,0.24)$ respectively. Therefore, mass customization improves customer quality integration both directly and indirectly through internal quality integration, whereas it only improves supplier quality integration indirectly through internal quality integration. We also find that the bias-corrected $95 \%$ confidence intervals of the indirect effects of product modularity on supplier and customer quality integration through internal quality integration are $(0.09,0.21)$ and $(0.10,0.23)$ respectively. Moreover, the bias-corrected $95 \%$ confidence intervals of the indirect effects of product modularity on internal and customer quality integration through mass customisation are $(0.07$, $0.19)$ and $(0.04,0.13)$ respectively. Therefore, product modularity improves internal quality integration both directly and indirectly through mass customization; supplier quality integration both directly and indirectly through internal quality integration; and customer quality integration indirectly through internal quality integration and mass customization. In addition, the bias-corrected $95 \%$ confidence interval of the indirect effect of internal quality integration on competitive performance through supplier quality integration is $(0.08,0.19)$. Therefore, internal quality integration improves competitive performance both directly and indirectly through supplier quality integration.

\section{Discussion and conclusions}

\subsection{Supplier quality integration}

We find that the direct impact of mass customization on supplier quality integration is not significant. Mass customization aims to provide individually designed products to customers in a timely manner and at close to mass production prices (Da Silveira et al., 2001; Tu et al., 2001). It also enables a manufacturer to develop production capabilities in terms of quality, 
delivery, flexibility, and productivity (Kortmann et al., 2014; Fogliatto et al., 2010). Hence, mass customization mainly has direct influences on a manufacturer's internal and customer quality management. Because mass customizers have operational strengths to integrate quality management processes internally, which builds a foundation for and facilitates supplier quality integration (Huo et al., 2014), mass customization enhances supplier quality integration indirectly through internal quality integration. Modular product designs allow a manufacturer to purchase separable components from suppliers, facilitating the manufacturer to diagnose potential quality problems collaboratively with the suppliers (Duray et al., 2000; Salvador, 2007). Product modularity also motivates a manufacturer to communicate with suppliers about quality considerations and design changes and to involve suppliers into product development and quality improvement projects because modules must be combined with other components. Hence, product modularity directly improves supplier quality integration. Product modularity allows functional departments to cooperate to solve conflict and quality problems by standardizing the interfaces between modules, improving internal quality integration. Hence, it also enhances supplier quality integration indirectly through internal quality integration. Supplier quality integration enables a manufacturer to develop its suppliers' capabilities on quality management and to influence the criteria suppliers adopted when they build their supply networks (Romano and Vinelli, 2001; Yeung, 2008). Manufacturers thus can control quality when their suppliers re-outsource production or source components from their supply chains (Foster, 2008). Therefore, supplier quality integration directly improves competitive performance.

\subsection{Internal quality integration}

Mass customization allows a manufacturer to respond to customer requirements quickly with low costs (Salvador et al., 2009). It thus drives functional departments to work interactively with each other and form cross-functional teams to solve quality problems, 
improving internal quality integration. Product modularity enables a manufacturer to absorb changes in customer requirements by reconfiguring and adapting modules and components creatively (Baldwin and Clark, 1997), which improve mass customization and facilitate functional departments to cooperate on decision making and coordinate their activities (Peng et al., 2011; Zhang et al., 2014). Hence, product modularity enhances internal quality integration both directly and indirectly through mass customization. Internal quality integration can improve the transparency on operational and strategic decisions and help functional departments to align objectives and act in a concerted way (Flynn and Zhao, 2015). It also creates an integrated interface that facilitates a manufacturer to engage suppliers in new product development and quality improvement (Lai et al., 2012), improving supplier quality integration. Hence, internal quality integration improves competitive performance both directly and indirectly through supplier quality integration.

\subsection{Customer quality integration}

By designing products as loosely coupled modules that can be sourced from suppliers and combined according to customer requirements, modularity mainly influences the design of upstream supply chains and internal product development and manufacturing processes (Salvador, 2007). Customers' operations are mainly influenced by the specification and conformance of a manufacturer's finished products which are not directly determined by the degree of modularity. In addition, customers' feedback on quality and delivery is mainly based on the perception of finished products. Customers may also lack the knowledge and skills to participate in the design of modules. Hence, a manufacturer's capability to modularize products does not directly influence customer quality integration. Mass customization usually requires

a manufacturer to learn from customers (Huang et al., 2008; Zhang et al., 2015b) and implement customer focus (Kristal et al., 2010). It enables a manufacturer to keep close contact with customers and acquire feedback on quality and delivery performance (Tu et al., 2004), 
improving customer quality integration. Internal quality integration can establish a cohesive platform that reduces the barriers for cooperating with customers on new product development and quality improvement (Lai et al., 2012), improving customer quality integration. Hence, product modularity can improve customer quality integration indirectly through mass customization and internal quality integration. This study also reveals that customer quality integration does not directly affect competitive performance. Researchers argue that downstream supply chains can mitigate the negative effects of quality problems and help a manufacturer to recover promptly from a product recall (Flynn and Flynn, 2005; Flynn and Zhao, 2015). A manufacturer can reduce product defects and rework by communicating with customers and involving customers in product design and quality improvement projects, reducing the costs of quality (Huo et al., 2014). Effective coordination and cooperation between a manufacturer and customers can also prevent quality problems and delays in delivery. Hence, customer quality integration may not bring a manufacturer competitive advantages and its major role is to provide a mechanism for the manufacturer to control and manage quality risks to avoid losses (Flynn and Zhao, 2015).

\subsection{Theoretical contributions}

This study contributes to mass customization, product modularity, and supply chain quality management literature. First, the majority of extant empirical studies focus on how to develop mass customization capability (e.g. Huang et al., 2008; Lai et al., 2012; Trentin et al., 2012; Zhang et al., 2015a). This study reveals that mass customization is positively associated with supply chain quality integration, improving current understandings on the consequences of mass customization. Researchers have found that traditional quality management practices, such as customer focus, process management, and cross-functional teams (Huang et al., 2008; Kristal et al., 2010; Liu et al., 2012b; Tu et al., 2004), are closely related to mass customization implementation. This study further reveals that mass customization is an enabler for a 
manufacturer to integrate with suppliers and customers and internally on quality management, and it improves internal, supplier, and customer quality integration in different ways, extending extant knowledge on the complex relationships between mass customization and quality management (Kristal et al., 2010).

Second, the findings show that product modularity is positively associated with supply chain quality integration, enhancing current understandings on the impacts of modular product design on supply chain and quality management (Salvador, 2007). The majority of extant studies focus on the effects of modularity on a manufacturer's internal manufacturing capabilities (e.g. Duray et al., 2000; Peng et al., 2011; Zhang et al., 2014). Our results show that product modularity also facilitates a manufacturer to integrate quality management both among functional departments and with suppliers and customers (Tu et al., 2004; Flynn and Zhao, 2015). In addition, this study reveals that product modularity improves supplier and customer quality integration indirectly through internal quality integration, and improves internal and customer quality integration indirectly through mass customization. These findings provide insights into the complex relationships between product modularity and internal, supplier, and customer quality integration and the joint effects of product modularity and mass customization on supply chain quality management (Huo et al., 2014; Fogliatto et al., 2010).

Third, this study links a manufacturer's design and production capabilities with quality management within internal and external supply chain contexts, and clarifies the relationships between mass customization, product modularity, supply chain quality integration, and competitive performance, improving existing knowledge on the antecedents and consequences of supply chain quality management (Robinson and Malhotra, 2005; Sila et al., 2006; Huo et al., 2014). The results show that mass customization and product modularity improve supplier and customer quality integration indirectly through internal quality integration, and internal 
quality integration not only improves customer and supplier quality integration but also improves competitive performance indirectly through supplier quality integration, enhancing current understandings on the interrelationships among supplier, internal, and customer quality integration (Foster, 2008; Huo et al., 2014). The findings shed light on how a manufacturer can develop effective supply chain quality management systems and prevent quality problems by improving design and production capabilities, and on the different roles played by supplier, internal, and customer quality integration in improving competitive performance (Flynn and Flynn, 2005; Foster, 2008).

\subsection{Managerial implications}

This study can provide guidelines for managers on how to implement supply chain quality integration. We suggest managers apply the manufacturing and organizational design practices that enhance mass customization capability to manage internal and supply chain quality issues. For example, a manufacturer can apply time-based manufacturing practices (Tu et al., 2001), adopt sociotechnical work-design principles (Liu et al., 2006), implement cross-functional integration and coordination (Liu et al., 2012b; Zhang et al., 2014), design a flat organizational structure (Zhang et al., 2014), use information technologies to support strategic and operational decision making (Jitpaiboon et al., 2013; Trentin et al., 2012), and develop knowledge management systems to learn from supply chain partners and create knowledge internally (Huang et al., 2008; Zhang et al., 2015c). In addition, we suggest managers apply modular product designs and product platforms to reduce production varieties ( $\mathrm{Tu}$ et al., 2004). Common assemblies and components can be used to simplify supply chains (Salvador, 2007) and increase the visibility of the supply chains (Flynn and Zhao, 2015). We also suggest managers implement mass customization and product modularity at the same time to capture their synergetic effects on supply chain quality integration.

This study can also help managers to devise a supply chain quality management system 
to gain competitive advantages. We suggest that managers focus on internal and supplier quality integration at the same time to full reap their benefits on competitive performance improvement (Huo et al., 2014). For example, managers can design special routines and procedures to guide cooperation and collaboration among functional departments (Flynn and Flynn, 2005). Processes and policies can be developed to build horizontal channels for crossfunctional interactions and to solve conflict among employees. In addition, it is important that manufacturers organize cross-functional teams to solve quality problems and conduct quality improvement projects (Srinivasan and Kurey, 2014). Incentive plans can be created to motivate team members to contribute to decision making. Moreover, we suggest managers incorporate suppliers in their quality visions and improvement efforts. Managers can maintain close communications with suppliers about quality considerations to improve supply chain transparency (Zhao et al., 2013). Keeping cooperative relationships and building trust with suppliers can ensure that information is exchanged in an accurate and timely manner, reducing information asymmetries in a supply chain (Yeung et al., 2009). Investing in supplier development can improve the quality of components and thus reduce supply chain vulnerabilities and quality risks. We also suggest managers involve suppliers into new product development and quality improvement projects because suppliers can provide valuable knowledge and capabilities that can improve the competitiveness of a manufacturer's products and processes (Zhao et al., 2015c). Although researchers argue that quality integration with customers can prevent quality problems and reduce costs of product failures (Huo et al., 2014; Flynn and Zhao, 2015), managers should be aware that customer quality integration cannot directly improve competitive performance.

\subsection{Limitations and future research directions}

While this study makes significant theoretical and practical contributions, it has limitations that open up avenues for future research. First, this study focuses on product modularity. 
Researchers argue that the modularity principle can also be applied into process designs (Tu et al., 2004). It will be fruitful for future research to examine the joint effects of product and process modularity on supply chain quality integration. Second, this study focuses the impacts of mass customization and product modularity on supply chain quality integration. Researchers argue that supply chain quality management can be affected by other antecedents, including environmental conditions, such as competition hospitality and government regulations, and organization-wide approach (Huo et al., 2014; Flynn and Zhao, 2015). Moreover, the effects of mass customization and product modularity may be moderated by environmental uncertainty (Liu et al., 2012a) or mediated by manufacturing technologies and practices (Peng et al., 2011). Future studies can explore how the impacts of mass customization and product modularity on supply chain quality integration are influenced by business environments and production systems. Third, this study does not consider the product recall system which is an important component of downstream supply chain quality management (Flynn and Zhao, 2015). Future studies can link customer quality integration with product recall practices and explore their joint effects on operational and business performance.

\section{References}

Baldwin, C.Y., Clark, K.B., 1997. Managing in an age of modularity. Harvard Business Review, 75(5), 84-93.

Bryman, A., Bell, E., 2011. Business research methods (3rd ed). Oxford University Press, Oxford.

Da Silveira, G., Borenstein, D., Fogliatto, F.S., 2001. Mass customization: Literature review and research directions. International Journal of Production Economics, 72(1), 7-13.

Duray, R., Ward, P.T., Willigan, G.W., Berry, W.L., 2000. Approaches to mass customization: Configurations and empirical validation. Journal of Operations Management, 18(6), 605625. 
Flynn, B.B., Flynn, E.J., 2005. Synergies between supply chain management and quality management: Emerging implications. International Journal of Production Research, 43(16), 3421-3436.

Flynn, B.B., Huo, B., Zhao, X., 2010. The impact of supply chain integration on performance: A contingency and configuration approach. Journal of Operations Management, 28(1), 5871.

Flynn, B.B., Zhao, X., 2015. Global supply chain quality management: Product recalls and their impact, in: Kumar, S. (Ed.), Supply chain integration: Modeling, optimization, and applications. CRC Press, Boca Raton.

Fogliatto, F.S., Da Silveira, G., Borenstein, D., 2010. The mass customization decade: An updated review of the literature. International Journal of Production Economics, 138(1), $14-25$.

Fornell, C., Larcker, D.F., 1981. Evaluating structural equation models with unobservable variables and measurement errors. Journal of Marketing Research, 18(1), 39-50.

Foster, S.T., 2008. Towards an understanding of supply chain quality management. Journal of Operations Management, 26(4), 461-467.

Hu, L., Bentler, P.M., 1999. Cutoff criteria for fit indices in covariance structure analysis: Conventional criteria versus new alternatives. Structural Equation Modeling, 6(1), 1-55.

Huang, X., Kristal, M.M., Schroeder, R.G., 2008. Linking learning and effective process implementation to mass customization capability. Journal of Operations Management, 26(6), 714-729.

Huo, B., 2012. The impact of supply chain integration on company performance: An organizational capability perspective. Supply Chain Management: An International Journal, 17(6), 596-610.

Huo, B., Zhao, X., Lai, F., 2014. Supply chain quality integration: Antecedents and 
consequences. IEEE Transctions on Engineering Management, 61(1), 38-51.

Jitpaiboon, T., Dobrzykowski, D.D., Ragu-Nathan, T.S., Vonderembse, M.A., 2013. Unpacking IT use and integration for mass customisation: A service-dominant logic view. International Journal of Production Research, 51(8), 2527-2547.

Kaynak, H., Hartley, J.L., 2008. A replication and extension of quality management into the supply chain. Journal of Operations Management, 26(4), 468-489.

Kortmann, S., Gelhard, C., Zimmermann, C., Piller, F.T., 2014. Linking strategic flexibility and operational efficiency: The mediating role of ambidextrous operational capabilities. Journal of Operations Management, 32(7/8), 475-490.

Kristal, M.M., Huang, X., Schroeder, R.G., 2010. The effect of quality management on mass customization capability. International Journal of Operations \& Production Management, 30(9), 900-922.

Lai, F., Zhang, M., Lee, D.M.S., Zhao, X., 2012. The impact of supply chain integration on mass customization capability: An extended resource-based view. IEEE Transactions on Engineering Management, 59(3), 443-456.

Lin, C., Chow, W., Madu, C., Kuei, C., Yu, P.P., 2005. Structural equation model of supply chain quality management and organizational performance. International Journal of Production Economics, 96(3), 355-365.

Liu, G., Shah, R., Schroeder, R.G., 2006. Linking work design to mass customization: A sociotechnical systems perspective. Decision Sciences, 37(4), 519-545.

Liu, G., Shah, R., Babakus, E., 2012a. When to mass customize: The impact of environmental uncertainty. Decision Siences, 43(5), 851-887.

Liu, G., Shah, R., Schroeder, R.G., 2012b. The relationships among functional integration, mass customisation, and firm performance. International Journal of Production Research, 50(3), 677-690. 
Miller, J.G., Roth, A.V., 1994. A taxonomy of manufacturing strategies. Management Science, 40(3), 285-304.

O’Leary-Kelly, S.W., Vokurka, R.J., 1998. The empirical assessment of construct validity. Journal of Operations Management, 16(4), 387-405.

Peng, D.X., Liu, G., Heim, G.R., 2011. Impacts of information technology on mass customization capability of manufacturing plants. International Journal of Operations \& Production Management, 31(10), 1022-1047.

Preacher, K., Hayes A. 2008. Asymptotic and resampling strategies for assessing and comparing indirect effects in multiple mediator models. Behavior Research Methods, 40(3):879-891.

Robinson, C.J., Malhotra, M.K., 2005. Defining the concept of supply chain quality management and its relevance to academic and industrial practice. International Journal of Production Economics, 96(3), 315-337.

Romano, P., Vinelli, A., 2001. Quality management in a supply chain perspective: Strategic and operative choices in a textile-apparel network. International Journal of Operations \& Production Management, 21(4), 446-460.

Salvador, F., 2007. Toward a product system modularity construct: Literature review and reconceptulization. IEEE Transctions on Engineeing Management 54(2), 219-240.

Salvador, F., de Holan, P.M., Piller, F., 2009. Cracking the code of mass customization. MIT Sloan Management Review, 50(3), 71-78.

Saunders, M., Lewis, P., Thornhill, A., 2012. Research methods for business students. (6th ed.). Pearson, Harlow.

Sila, I., Ebrahimpour, M., Birkholz, C., 2006. Quality in supply chains: An empirical analysis. Supply Chain Management: An International Journal, 11(6), 491-502.

Srinivasan, A., Kurey, B., 2014. Creating a culture of quality. Harvard Business Review, 92(4), 
Trentin, A., Forza, C., Perin, E., 2012. Organisation design strategies for mass customisation: An information-processing-view perspective. International Journal of Production Research, 50(14), 3860-3877.

Tu, Q., Vonderembse, M.A., Ragu-Nathan, T.S., 2001. The impact of time-based manufacturing practices on mass customization and value to customer. Journal of Operations Management, 19(2), 201-217.

Tu, Q., Vonderembse, M.A., Ragu-Nathan, T.S., Ragu-Nathan, B., 2004. Measuring modularity-based manufacturing practices and their impact on mass customization capability: A customer-driven perspective. Decision Sciences, 35(2), 147-168.

Yeung, A.C.L., 2008. Strategic supply management, quality initiatives, and organizational performance. Journal of Operations Management, 26(4), 490-502.

Yeung, J.H.Y., Selen, W., Zhang, M., Huo, B., 2009. The effects of trust and coercive power on supplier integration. International Journal of Production Economics, 120(1), 66-78.

Zhang, M., Lettice, F., Zhao, X., 2015a. The impact of social capital on mass customization and product innovation capabilities. International Journal of Production Research, 53(1), $5251-5264$.

Zhang, M., Qi, Y., Zhao, X., Duray, R., 2015b. Mass customization system: Complementarities and performance consequences. International Journal of Logistics: Research and Applications, 18(6), 459-475.

Zhang, M., Zhao, X., Lyles, M., Guo, H., 2015c. Absorptive capacity and mass customization capability. International Journal of Operations \& Production Management, 35(9), 12751294.

Zhang, M., Zhao, X., Qi, Y., 2014. The effects of organizational flatness, coordination, and product modularity on mass customization capability. International Journal of Production 
Economics, 158,145-155.

Zhao, L., Huo, B., Sun, L., Zhao, X., 2013. The impact of supply chain risk on supply chain integration and company performance: A global investigation. Supply Chain Management: An International Journal, 18(2), 115-131.

\section{Appendix A Measurement items}

Mass customization (Respondents: PE, PDM, PS)

We are highly capable of large scale product customization.

We can easily add significant product variety without increasing cost.

We can customize products while maintaining high volume.

We can add product variety without sacrificing quality.

Our capability for responding quickly to customization requirements is very high.

\section{Product modularity (Respondents: IM, PDM, PE)}

Our products are modularly designed, so they can be rapidly built by assembling modules. We have defined product platforms as a basis for future product variety and options.

Our products are designed to use many common modules.

Supplier quality integration (Respondents: QM, IM)

We maintain cooperative relationships with our suppliers.

We help our suppliers to improve their quality.

We maintain close communications with suppliers about quality considerations and design changes.

Our key suppliers provide input into our product development projects.

Our suppliers are actively involved in our new product development process.

We mostly use suppliers that we have certified.

We actively engage suppliers in our quality improvement efforts.

Internal quality integration (Respondents: PE, PM, QM, SP)

The functions in our plant work well together.

The functions in our plant cooperate to solve conflicts between them when they arise.

Our plant's functions coordinate their activities.

Our plant's functions work interactively with each other.

During problem-solving sessions, we make an effort to get all team members' opinions and ideas before making a decision.

Our plant forms teams to solve problems.

In the past three years, many problems have been solved through small group sessions.

Problem-solving teams have helped improve manufacturing processes at this plant.

Customer quality integration (Respondents: QM, SP)

We are frequently in close contact with our customers.

Our customers give us feedback on our quality and delivery performance.

Our customers are actively involved in our product design process.

Our processes are certified or qualified by our customers. 
Our customers involve us in their quality improvement efforts.

Competitive performance (Respondents: PM)

Unit cost of manufacturing

Conformance to product specifications

On time delivery performance

Flexibility to change product mix

Flexibility to change volume

Inventory turnover

Cycle time (from raw materials to delivery)

Product capability and performance

On time new product launch

Product innovativeness

Note: IM: Inventory manager; PDM: Product development manager; PE: Process engineer; PM: Plant manager; QM: Quality manager; SP: Supervisor; PS: Plant superintendent 


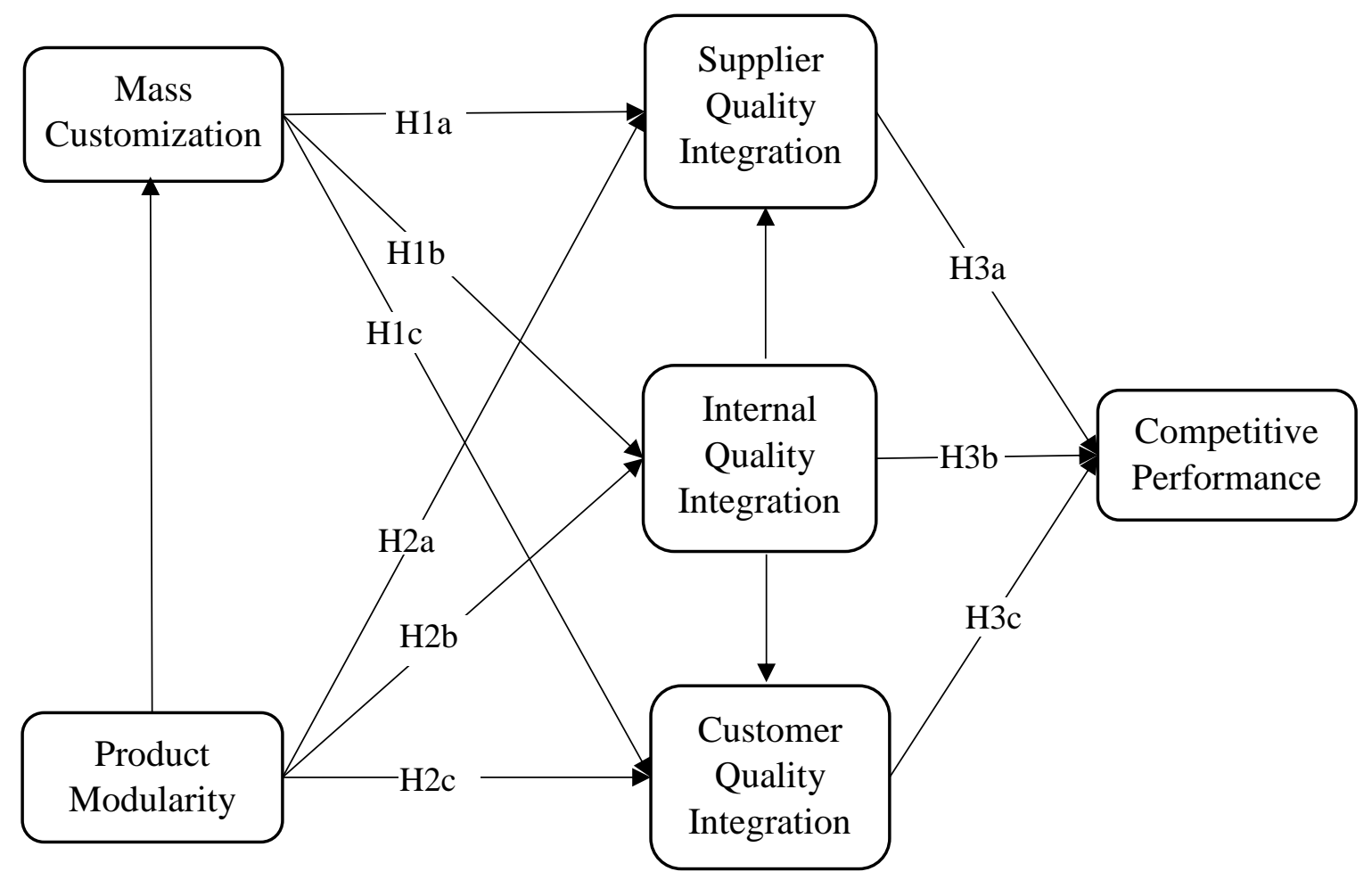

Figure 1. Conceptual model

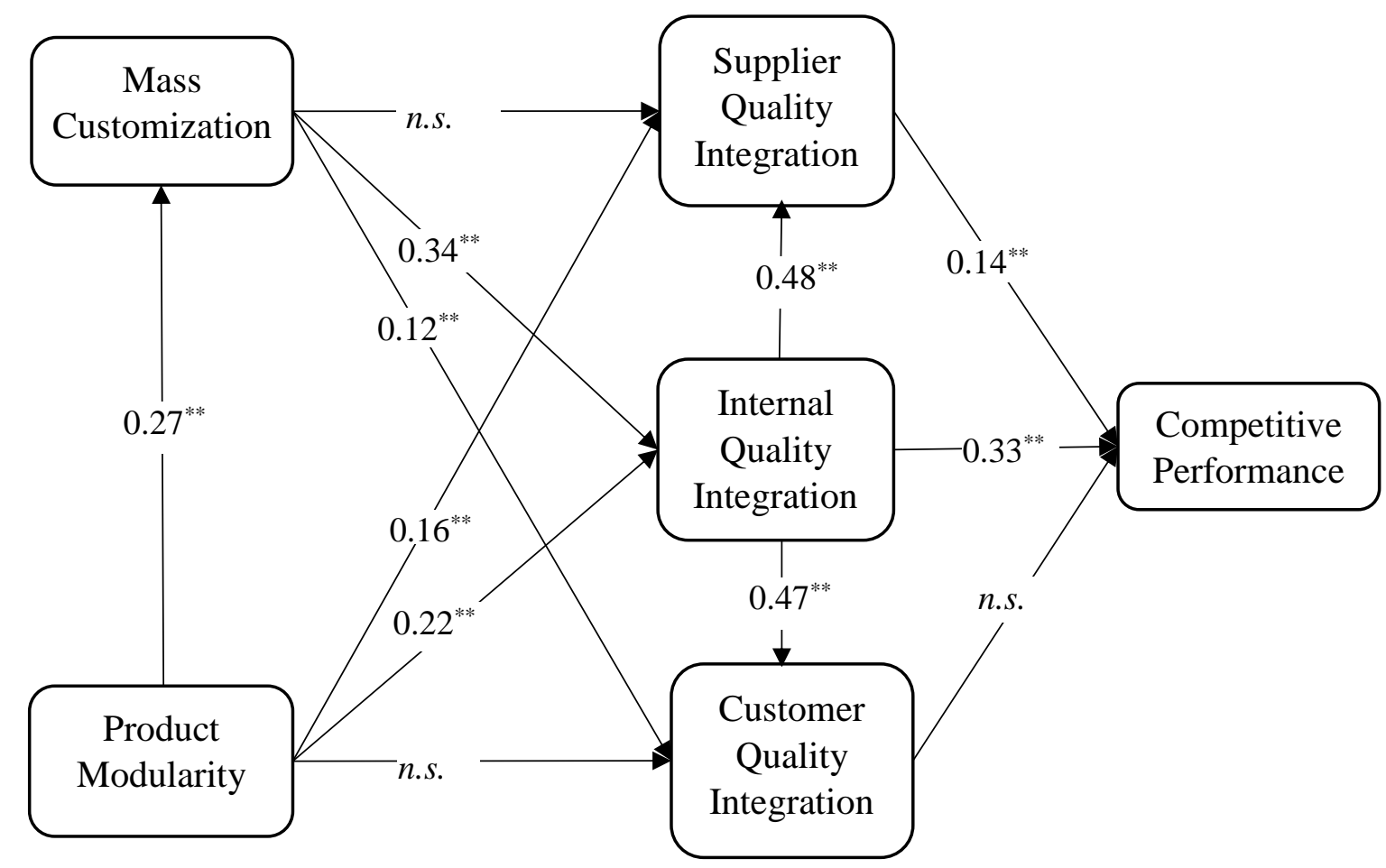

Note: ${ }^{* *} \mathrm{p}<0.05 ;$ n.s. not significant

Figure 2. Structural model with path coefficient estimates 
Table 1. Distribution of samples

\begin{tabular}{lcccc}
\hline \multirow{2}{*}{ Country } & \multicolumn{3}{c}{ Industry } & \multirow{2}{*}{ Total } \\
\cline { 2 - 4 } & Electronics & Machinery & Auto-supplier & \\
\hline Austria & 10 & 7 & 4 & 21 \\
China & 21 & 16 & 14 & 51 \\
Finland & 14 & 6 & 10 & 30 \\
Germany & 9 & 13 & 19 & 41 \\
Italy & 10 & 10 & 7 & 27 \\
Japan & 10 & 12 & 13 & 35 \\
Spain & 9 & 9 & 10 & 28 \\
South Korea & 10 & 10 & 11 & 31 \\
Sweden & 7 & 10 & 7 & 24 \\
U.S.A. & 9 & 11 & 9 & 29 \\
\hline Total & 109 & 104 & 104 & 317 \\
\hline
\end{tabular}

Table 2. Descriptive statistics

\begin{tabular}{lcccccc}
\hline & MC & PM & SQI & IQI & CQI & CP \\
\hline Mass customization (MC) & 0.71 & & & & & \\
Product modularity (PM) & $0.22^{* *}$ & 0.81 & & & & \\
Supplier quality integration (SQI) & $0.21^{* *}$ & $0.32^{* *}$ & 0.76 & & & \\
Internal quality integration (IQI) & $0.35^{* *}$ & $0.19^{* *}$ & $0.51^{* *}$ & 0.71 & & \\
Customer quality integration (CQI) & $0.20^{* *}$ & -0.09 & $0.46^{* *}$ & $0.47^{* *}$ & 0.74 & \\
Competitive performance (CP) & $0.24^{* *}$ & $0.20^{* *}$ & $0.23^{* *}$ & $0.37^{* *}$ & $0.11^{* *}$ & 0.69 \\
\hline Cronbach's Alpha & 0.76 & 0.74 & 0.88 & 0.86 & 0.79 & 0.80 \\
\hline Composite reliability & 0.84 & 0.85 & 0.90 & 0.89 & 0.86 & 0.85 \\
\hline Average variance explained (AVE) & 0.51 & 0.65 & 0.57 & 0.51 & 0.55 & 0.47 \\
\hline
\end{tabular}

Note: ${ }^{* *} p<0.01$. The square root of AVE is shown on the diagonal of each matrix in italic, and the inter-construct correlation is shown off the diagonal. 